\title{
Prescribing Individually Tailored Exercise as a Means of Increasing Health Promotion Among University Faculty, Staff, and Students
}

\author{
Robert G. Blair, Becky Keele, Charles Kozel \\ New Mexico State University
}

\begin{abstract}
The purpose of the study was to develop and monitor an individualized exercise health promotion program for faculty, staff, and students at the College of Health and Social Services (CHSS) at New Mexico State University. It was hypothesized that participants would: 1) increase the number of minutes exercised per week; 2) reduce their body weight and body mass index; and 3) report an increase in their Quality of Life. At pretest, the more participants exercised, the higher they rated their quality of life. These differences were significant. Other results showed a non-significant trend toward an increase in duration of minutes exercised, a decrease in body mass, and an increase in quality of life.
\end{abstract}

(c) 2007 Californian Journal of Health Promotion. All rights reserved.

Keywords: exercise, fitness, worksite, weight management

Given the demands of preparing for classes, committee work, and other extracurricular activities, university faculty, staff, and students often neglect exercise. Similar to the general population, as much as $30 \%$ to $59 \%$ of the adult United States population has a sedentary lifestyle (McAuley \& Courneya, 1993).

The purpose of this study was to develop and monitor a health promotion program that provided an individualized exercise intervention (IEI) for participants from Faculty, Staff, and Students in the College of Health and Social Services (CHSS) at New Mexico State University. Following the IEI, researchers would evaluate the impact of exercise on participant's quality of life. According to previous research, regular physical activity enhances psychological well-being (Burnham \& Wilcox, 2002; Dishman et al., 2006; Centers for Disease Control and Prevention, 2003). Emery et al. (1998) suggest that exercise may enhance psychological functioning through several pathways: enhanced self-efficacy from the ability to perform physical activities, release of natural opiates in the brain, and increased social support from the exercise setting. However, only $35 \%$ of college-aged persons reported engaging in vigorous physical activity on a regular basis (Mack \& Shaddox, 2004). Given the connection between exercise and perceived quality of life, it was hypothesized that participants in this research would report higher levels of quality of life. Further it was hypothesized that a greater number of minutes exercised would be positively correlated with scores on the quality of life survey.

\section{Methods}

Following approval from the university institutional review board, flyers were sent out inviting faculty, staff, and students in the College of Health and Social Services (CHSS) to participate in an exercise program. Personal invitations to participate were also made by the research team. From the flyers and invitations, a convenience sample of 84 faculty, staff, and students from the CHSS at New Mexico State University were recruited. Prior to the intervention (individualized exercise intervention) and at the end of the research study, participants were surveyed regarding their demographics, physical health, age, weight; body mass index (BMI); types of exercise they enjoyed; and the number of minutes exercised during previous weeks (see Table 1). 
Table 1

Demographic Characteristics of Participants (Pretest)

\begin{tabular}{|l|c|c|}
\hline Demographic Characteristic & N & Percent \\
\hline Participants & & \\
\hline Faculty & 22 & 26.0 \\
\hline Staff & 24 & 29.0 \\
\hline Students & 38 & 45.0 \\
\hline Total & 84 & \\
\hline Gender & & \\
\hline Women & 72 & 85.7 \\
\hline Men & 12 & 14.3 \\
\hline Marital Status & & \\
\hline Married & 41 & 49.0 \\
\hline Single & 26 & 43.0 \\
\hline Have Children & 56 & \\
\hline Ethnicity & & \\
\hline Anglo & & 48.8 \\
\hline Mexican American & & 30.2 \\
\hline African American & & 3.5 \\
\hline Native American & & 1.2 \\
\hline Other & & 12.8 \\
\hline Chronic Disease & & \\
\hline Yes & & 21.2 \\
\hline No & & 63.0 \\
\hline College Degree & & \\
\hline
\end{tabular}

The 'Stages of Exercise Scale' was used to measure current patterns of exercise (Cardinal, 1995). This instrument uses a Likert scale with a range of 0-4 that measured participants current exercise patterns ('I presently do not exercise and do not plan to start exercising in the next 6 months, to I presently exercise on a regular basis and have been doing so for longer than 6 months').

The quality of Life Enjoyment and Satisfaction Questionnaire (Short form) (Q-LES-Q) was used to assess participants quality of life (Endicott et. al., 1993). This self-report instrument scores responses on a 5-point scale ('not at all or never' to 'frequently or all the time'), with higher scores indicating better enjoyment and satisfaction with specific life domains. The instrument contains 16 questions, however, only 14 of the 16 questions are computed in the overall score (Ritsner et al., 2000). According to
Rapaport et al. (2005), the Q-LES-Q (short form) test-retest reliability (intraclass correlation coefficient) was 0.86 and the internal consistency (Cronbach's alpha) was 0.90 . Ritsner et al. (2000) note the short form of this instrument shows high correlation $(\mathrm{r}=0.93)$ with the general index and the same domains of the basic Q-Les-Q. This instrument is also inversely associated with severity of general psychopathology, depressive and negative symptoms, emotional distress, and is positively associated with self-efficacy, self-esteem and social support (Endicott et. al., 1993; Ritsner et al., 2000).

Following the pretest survey, participants were e-mailed an exercise prescription tailored to their individual exercise wants and needs (see Appendix A). For the next three months, forms were provided and participants were sent a weekly email to encourage them to complete and 
submit a summary of the types of exercise in which they engaged during the week, and the total number of minutes they exercised during that week. Following this three-month period, a post-test survey was completed to determine participants exercise routines, minutes exercised, weight and body mass, and the overall quality of participant's life. However, only 47 of the original 84 participants completed the survey at posttest. This large drop-out rate (44\%) seems to support the conclusions of McAuley \& Courneya (1993), who report that about $50 \%$ of individuals who initiate an exercise program drop out within three to six months. Table 2 summarizes exercise and weight patterns of participants at pre- and posttest.

\section{Findings}

At pretest, comparing participant's current stage of exercise with their quality of life score (QLES-Q), the more participants exercised, the higher they rated their Q-LES-Q. Based on ANOVA, differences between these groups were significant (p. < .020) (see Table 3). Q-LES-Q scores by current stage of exercise were also examined at posttest. No significant differences were noted.

Q-LES-Q scores were examined by participant's status: student, staff, or faculty. Differences between these groups were not significant (see Table 4).

Table 2

Exercise \& Weight Patterns

\begin{tabular}{|l|c|c|}
\hline \multicolumn{1}{|c|}{ Characteristics } & Pretest & Posttest \\
\hline More than one activity (\%) & 32.6 & 43.0 \\
\hline Not exercising (\%) & 41.9 & \\
\hline Difficulty maintaining activity (\%) & 54.0 & \\
\hline States of Exercise Scale (SOES) & & \\
\hline Do not exercise, but plan to (\%) & 22.1 & 6.0 \\
\hline Exercise but not regularly (\%) & 40.0 & 47.0 \\
\hline Exercise regularly but less than 6 months (\%) & 16.3 & 19.0 \\
\hline Current regular exercisers (\%) & 18.6 & 23.0 \\
\hline Not reported (\%) & 3.0 & 5.0 \\
\hline & & \\
\hline Weight (lbs.) & 172.87 & 175.06 \\
\hline Waist circumference (inches) & 36.54 & 35.07 \\
\hline Body fat (\%) & 35.26 & 34.98 \\
\hline Body mass index (BMI) & 28.85 & 28.77 \\
\hline
\end{tabular}

Table 3

Stages of Exercise Scale (SOES) and corresponding quality of life scores

\begin{tabular}{|l|c|c|c|c|}
\hline \multicolumn{1}{|c|}{ Scale Items } & $\begin{array}{c}\text { Pre-test } \\
\mathbf{N = \mathbf { 8 4 }}\end{array}$ & $\begin{array}{c}\text { Quality of Life } \\
\text { score }\end{array}$ & $\begin{array}{c}\text { Post-test } \\
\mathbf{N = \mathbf { 4 7 }}\end{array}$ & $\begin{array}{c}\text { Quality of Life } \\
\text { score }\end{array}$ \\
\hline Do not exercise and not starting & 1 & 42.29 & & \\
\hline $\begin{array}{l}\text { Do not exercise but plan to start in next 6 } \\
\text { months }\end{array}$ & 19 & 44.11 & 2 & 45.79 \\
\hline Exercise but not regularly & 34 & 49.33 & 21 & 49.19 \\
\hline Exercise regularly but less than 6 months & 14 & 50.35 & 9 & 51.41 \\
\hline $\begin{array}{l}\text { Exercise regularly and have been more than 6 } \\
\text { months }\end{array}$ & 16 & 53.13 & 11 & 51.84 \\
\hline Missing & 1 & & 4 & \\
\hline
\end{tabular}


Table 4

Pre- and posttest quality of life scores by status

\begin{tabular}{|l|c|c|c|c|}
\hline & $\begin{array}{c}\text { N = 84 } \\
\text { (pretest) }\end{array}$ & $\begin{array}{c}\text { Q-LES-Q } \\
\text { (pretest) }\end{array}$ & $\begin{array}{c}\mathbf{N}=\mathbf{4 7} \\
\text { (posttest) }\end{array}$ & $\begin{array}{c}\text { Q-LES-Q } \\
\text { (posttest) }\end{array}$ \\
\hline Faculty & 22 & 49.84 & 20 & 50.80 \\
\hline Staff & 24 & 48.64 & 9 & 49.53 \\
\hline Students & 38 & 48.67 & 15 & 49.40 \\
\hline Missing & 0 & & 3 & \\
\hline
\end{tabular}

Q-LES-Q scores at pretest (49) were compared with posttest scores (50.18) for participants who completed the study. Results indicated no significant differences. Finally, participants were asked to indicate whether or not they were currently exercising. Results of this indication and Q-LES-Q scores showed no significant differences. Sixty-six percent of the participants rated their overall life satisfaction as good to very good at pre-test, and $76.6 \%$ rated it as good to very good at post-test. These differences were not significant. For participants who completed both pre- and posttests, A paired samples t-test was conducted. Results indicate that pretest QLES-Q scores were 49.34 vs. 49.89 for posttest. These small differences were not significant. For the overall life satisfaction question, despite fewer numbers, more participants rated this better at post-test (16) as compared with pretest (12). These differences were not significant based on the Wilcoxon Signed Ranks Test ( $\mathrm{z}=-$ $.521, \mathrm{p}=.603)$.

\section{Conclusion}

At the beginning of the study the majority of participants appeared motivated to increase their exercise regime. However, that enthusiasm seemed to quickly wane as the responsibilities of semester took hold. Participants complained that papers were due or that they had other pressing matters that prevented them from exercising regularly. As a research team, we hypothesized that the large rate of attrition was due to nonexercisers dropping out before developing the habit of regular exercise. However, testing the relationship between the stage of exercise reported by the participant, and the probability of dropping out of the study revealed no significant differences based on the Wilcoxon Signed Ranks Test ( $\mathrm{z}=-.843, \mathrm{p}=.399)$. Therefore, we were left to speculate as to the large rate of attrition. Probable reasons include the fact that significant changes in behavior are difficult to maintain; and that academic responsibilities often interfere with the best of exercise intentions. Further, the accountability measures we employed were only minimally effective. We tried to hold participants accountable for weekly exercise by emailing them weekly and asking that they email us back their exercise regime during the previous week. However, this tactic was only minimally effective; participants were able to easily ignore these emails. Keele-Smith \& Leon (2003) previously used telephone contact with participants to increase exercise adherence. Their contact appeared to be more difficult to ignore, therefore participants in that study reported greater exercise adherence and less attrition. In future studies the effectiveness of e-mail vs. telephone calls regarding exercise adherence should be examined.

In summary, at pretest there was a positive correlation between exercise stages and perceived quality of life. The more participants exercised, the greater their perception of their quality of life. Other findings of this study were not statistically significant. However, in nearly every analysis there were clear trends indicating exercise and perceived quality of life were positively correlated. Further, fourteen participants increased their stage of exercise as measured by using the SOES scale. For example, they moved from "do not exercise but plan to" to "exercise but not regularly." Twentyfour participants remained at the same stage of 
exercise, and five had a reduction in their stage of exercise. There were also non-significant indications that as individuals started and maintained an exercise program; their perceived quality of life improved. For example, pre- and post-test Q-LES-Q scores were analyzed on the 14 participants who were able to increase their stage of exercise. Results, although not statistically significant, show a trend towards a positive correlation between exercise and QLES-Q scores (pretest Q-LES-Q $=48.27 \&$ posttest Q-LES-Q = 50.29, t =1.074, \& $\mathrm{p}=.30$ ).

In addition to changes in Q-LES-Q scores, this exercise health promotion program may have had another impact. At pretest, 36\% of the sample indicated exercising regularly; whereas $43 \%$ indicated exercising regularly at posttest. This may indicate that programs designed to increase exercise among participants, if designed well and carried out for a sufficient length of time, may accomplish their goal. However, it may also indicate that non-exercisers, and irregular exercisers, although enthusiastic about beginning an exercise program, are easily discouraged. Without adequate supports and accountability measures, these participants will frequently drop out of exercise programs.

\section{References}

Burnham, T., and Wilcox, A. (2002). Effects of exercise on physiological and psychological variables in cancer survivors. Medicine \& Science in Sports \& Exercise, 34, 1863-1867.

Centers for Disease Control and Prevention. (2003). U. S. physical activity statistics, 2003. Atlanta, GA: U. S. Department of Health and Human Services.

Cardinal, B. (1995). The stages of exercise scale and stages of exercise behavior in female adults. Journal of Sports Medicine and Physical Fitness, 35(2), 87-92.

Dishman, R., Hales, D., Pfeiffer, K., Felton, G., Saunders, R., Dowda, M., and Pate, R. (2006). Physical self-concept and self-esteem mediate cross-sectional relations of physical activity and sport participation with depression symptoms among adolescent girls. Health Psychology, 25, 396-407

Emery, C., Schein, C., Hauck, R. Macintyre, Neil, R. (1998). Psychological and cognitive outcomes of a randomized trial of exercise among patients with chronic obstructive pulmonary disease. Health Psychology, 17, 232-240.

Endicott, J., Nee, John, Harrison, W., and Blumenthal, R. (1993). Quality of life enjoyment and satisfaction questionnaire: A new measure. Psychopharmacology Bulletin, 25, 321-326.

Rapaport, M., Clary, C., Fayyad, R, and Endicott, J. (2005). Quality-of-life impairment in depressive and anxiety disorders. American Journal of Psychiatry; 162, 1171-1178.

Keele-Smith, R., and Leon, T. (2003). Evaluation of individually tailored interventions on exercise adherence. Western Journal of Nursing Research, 25, 623-640.

McAuley, E., \& Courneya, K. (1993) Adherence to exercise and physical activity as health-promoting behaviors: Attitudinal and self-efficacy influences. Applied and Preventative Psychology, 2, 6577.

Mack, M., and Shaddox, L. (2004). Changes in Short-term attitudes toward physical activity and exercise of university personal wellness students. College Student Journal, 38, 587-593.

Ritsner, M., Modai, I., Endicott, J., Rivkin, O. Nechamkin, Y, Barak, P., Goldin, V., Ponizovsky, A. (2000). Differences in quality of life domains, psychopathological and psychosocial factors in psychiatric patients. Journal of Clinical Psychology, 6, 880-889.

Author Information

Robert G. Blair, Ph.D.*

Associate Professor

New Mexico State University

School of Social Work 
E-Mail: roblair@nmsu.edu

Becky Keele, Ph.D.

Associate Professor

New Mexico State University

School of Nursing

Charles Kozel, Ph.D., M.P.H., C.H.E.S.

Associate Professor

New Mexico State University

Dept. of Health Science

* corresponding author 


\section{Appendix A \\ Example of an Individualized Exercise Intervention (IEI)}

Since the health benefits of exercise appear to be important to you, I would encourage you to engage in positive self-talk and visual reminders regarding the benefits of exercise.

Also, remind yourself about other serious benefits of exercise such as better mood, increase productivity in other areas of life, better sleep, and being more able to meet goals by having increase in energy levels. Monopolize on your need to meet goals by learning how to prioritize and make exercise an important goal.

Integrate physical activity within your routine day (such as taking stairs instead of elevator, parking farther away from workplace).

Enjoyment of the physical activity itself is important to you. Identify reasons for this enjoyment and reinforce them through positive self-talk. What activity currently or in the past could you honestly say you truly enjoyed. If you can't identify one, what activity(s) do you think you would enjoy? Focus on the sensations that you feel when exercising and identify the ones you agree with. Make a chart and put it in a visible area as a reminder each day. . . Example sensations are: sweating, heart racing, energized, strength, relaxed, excited, fun, feel a rush/high, breathless.

Some level of support system needs to be in place to promote optimal ability to maintain a regular physical activity. Try to elicit a friend/family member to provide that support through a weekly reminder e-mail/phone call. Probably needs to be daily for the first few weeks unless you have already been exercising regularly for awhile. I you are interested in finding an accountability partner/exercise buddy, let us know and we can try to match you up with someone else in the program.

You could benefit from help with organization/planning/prioritizing activities through educational resources/examples. Use visual reminders for exercising (place on refrigerator, bedroom/bathroom, door, etc.)

Remember, you are in control when you are successful in participating in regular physical activity. Use reminders of your physical/mental gains from exercising such as increasing muscle mass/tone, maintenance of ideal body wt/body fat, etc.

Competitive/challenging/fun exercise would be a good match for you. Types of activities that you might consider are: aerobic dance or step aerobics, cycling, classes with music. Competitive group sports

Your current \% body fat is 43.8 (ideal range 21 to 33)

Your current BMI is 32.2 (ideal range 21 to 25)

Start keeping a record of your steps each day as per your pedometer. Feel free to ask questions and voice any concerns as the study progresses. We are very excited that you are participating and want to achieve a healthy fitness level. 